\title{
Conceptual Metaphor and Vocabulary Teaching in the EFL Context
}

\author{
Xin Fang \\ School of Foreign Languages, Southwest University, Chongqing, China \\ Email: jenny19880708@126.com
}

Received 2 April 2014; revised 7 May 2014; accepted 15 May 2014

Copyright (C) 2014 by author and Scientific Research Publishing Inc. This work is licensed under the Creative Commons Attribution International License (CC BY). http://creativecommons.org/licenses/by/4.0/

(c) (7) Open Access

\begin{abstract}
Metaphor, as a matter of thought, a way of cognition, is pervasive in our everyday life and language. As human beings' important cognitive way, metaphor also serves as one of the important ways for language to develop, including vocabulary. Traditionally, most students memorize vocabulary mechanically with unpleasant results. They don't realize most words come from metaphorical way, and metaphor is an important process of word meanings expanding and evolution. This paper will give a brief discussion about conceptual metaphor theory and analyze how to apply this theory into vocabulary teaching in the EFL context, in order to help learners to learn vocabulary thoroughly, systematically, and efficiently.
\end{abstract}

\section{Keywords}

Metaphor, Cognition, Conceptual Metaphor Theory, Vocabulary Teaching

\section{Introduction}

Language is a building with vocabulary as bricks. Vocabulary, as an important part of language, is the bridge that connects us with others and transmits our mind and thought about the world. So in English teaching, vocabulary is a very important part and teaching vocabulary well can help students use English fluently and speak it smoothly. For many years, vocabulary teaching has been a very headache part for teachers and students, and many students also feel that poor vocabulary partly prevents them advancing. How to teach students to learn vocabulary well becomes an important theme in English teaching. Cognitive linguistics is based on human experience of the world and the way they perceive and conceptualize the world. Conceptual metaphor theory is one of the most important theories in cognitive linguistics. It takes metaphor into cognitive field and it claims that metaphor is not only a figure of speech, but also a way of cognition. Conceptual metaphor theory can help English teachers teach English well and make students easily master vocabulary in this language. So this paper will 
introduce it and discuss how to apply this theory into vocabulary teaching in the EFL context.

\title{
2. Conceptual Metaphor Theory
}

\subsection{The Definition of Conceptual Metaphor}

The early 1980s witnessed the real beginning of cognitive metaphor study with the publication of Lakoff \& Johnson's book Metaphors We Live By, in which the remarkable conceptual metaphor theory was introduced and elaborated. It defines metaphor as one of the basic cognitive mechanisms that structure the way we formulate and understand abstract concepts (Lakoff \& Johnson, 1980). In order to substantiate the notion that metaphor is something we live by, Lakoff and Johnson hold that, "the essence of metaphor is to experience and understand one in terms of another" (Lakoff \& Johnson, 1980: p. 5). In other words, metaphor can be seen as a mapping from a source domain to a target domain.

Metaphor is more than a language phenomenon, a rhetoric device. It is a cognitive phenomenon fundamentally. Metaphoric thinking is a way for people to know things and establish the concepts in mind. In daily language communicative activities, metaphor is everywhere, and people always use metaphor to link two things which are similar. According to Lakoff and Johnson's statistics, more than 70 percent of English expressions arise from such metaphorical concepts, so it can be concluded that they permeate almost all the aspects of our life and are indeed what we live by.

\subsection{The Classification of Conceptual Metaphor}

In Lakoff and Johnson's view, conceptual metaphor is of three kinds-structural metaphor, orientational metaphor and ontological metaphor, all revealing irresistible associations between language and human experiences (Lakoff \& Johnson, 1980).

\subsubsection{Structural Metaphors}

Structural metaphor is the case "where one concept is metaphorically structured in terms of another" (Lakoff \& Johnson, 1980: p. 15). That is, a source domain can offer the framework or structure for a target domain. For instance, in the English expressions "He is rich in ideas" and "He has a wealth of ideas", the concept of "idea" is used as "money". We can see the structural metaphor "Ideas Are Money" here. In a word, the cognitive function for structural metaphor is to make people understand target A through the structure of source B.

\subsubsection{Orientational Metaphors}

"Orientational metaphors map basic experiences from the spatial domain onto abstract cognitive model." "Many human concepts must be structured by orientational metaphors" (Lakoff \& Johnson, 1980). Orientational metaphor has close relation with the structural features of our physical bodies, these prepositions are usually seen in this kind of conceptual metaphor, such as up-down, in-out, front-back, on-off, etc. We usually use "up" "high" to refer to good situation and "down" "low" to refer to bad situation. It implies the conceptual metaphors: "Happy Is Up, and Sad Is Down". Let's take UP and DOWN for examples:

\author{
HAPPY IS UP; SAD IS DOWN \\ I am feeling up. \\ Thinking about her always gives me a lift. \\ I'm feeling down. \\ My spirits sank.
}

\author{
HEALTH AND LIFE ARE UP; SICKNESS AND DEATH ARE DOWN \\ He's at the peak of health. \\ As to his health, he's way up there. \\ He fell ill. \\ He dropped dead.
}

\section{CONSCIOUS IS UP; UNCONSCIOUS IS DOWN}

Get up. 
He rises early in the morning.

They fell asleep.

He sank into a coma (Lakoff \& Johnson, 2003: p. 16).

In brief, orientational metaphors are not arbitrary, it is based on our physical and cultural experience. This kind of metaphors also reveals the evolution process of human thinking and their language.

\subsubsection{Ontological Metaphors}

Ontological metaphor is regarded as "ways of viewing ideas, activities, events, emotions, etc., as substances and entities" (Lakoff \& Johnson, 1980: p. 26). This kind of metaphor specifies that different kinds of objects are pervasive in our thought. Ontological metaphors are used to comprehend events, actions, activities and states. For example: if we use the expression "he falls into depression", we are using ontological metaphor "States As Containers"; if we use the expression "Did you see the English contest?" we are using the ontological metaphor "Events or Actions Are Objects" (Lakoff \& Johnson, 2003: p. 31).

\section{Conceptual Metaphor and Vocabulary Teaching in the EFL Context}

Words and phrases are the basic part in English teaching and learning. Murcia \& Rosensweig (1979: p. 242) ever put forward such idea that "A person who has learned maximum number of vocabulary but minimum number of structure is more favorable than a person who is opposite to this case in reading comprehension and basic language communication." Therefore, more and more English teachers and researchers have paid attention to the study of foreign language vocabulary teaching and learning approaches.

Of course, traditional English teaching methods have some positive effect on English vocabulary teaching, but they are not effective and systematic enough for vocabulary teaching. Many students memorize and recite words by rote. They cannot master these words' deep or extended meanings and they cannot use them appropriately. So, they still cannot get a high level in English learning. Selinker (1972) thinks that only 5\% of second language learners can reach the level of native speaker. So learners' vocabulary learning is still a big problem nowadays.

In order to teach and learn English well, teachers and students can learn conceptual metaphor theory to instruct their vocabulary teaching and learning. As we know, metaphor is an essential cognitive tool for human beings, we do not just exploit the metaphor linguistically, but we actually think of, or conceptualize, what they call the target concept via the source concept. Conceptual metaphor also has close relation with vocabulary acquisition. "In other words, when we use the English phrases, we establish the links between two concepts that do not seem to belong together by their very nature" (Ungerer, 2008). Teachers can also use conceptual metaphor to illustrate the changing process of language meaning and the relations of different meanings of words.

\subsection{Conceptual Metaphor and Polysemy}

Mark Johnson (1987) said that "polysemy can be defined and understood as the phenomenon in which a single word may have many different meanings which are systematically related to each other." Most polysemies are not constructed randomly. They are based on the metaphorical usage of the target language. According to the cognitive view, polysemy is a categorizing phenomenon which contains a prototype and its extended meanings. Usually, the original meaning of a polysemous word comes from our concrete experience, and then its relevant meanings come into being in terms of the prototype. For example, originally, "head" means "the upper part of the body, including the eyes, nose, mouth and brain". Based on this meaning, we often say the head of government, "head" means "chief person of a group or organization"; have a good head for business, "head" means "mental ability or natural talent as specified"; at the head of the page, "head" means "top or highest part", etc. all these meanings of "head" have close relationship with its original meaning.

In polysemy teaching process, teachers should first help students realize the pervasive existence of conceptual metaphors in English, then show students the word's prototype meaning and sub-meanings based, on the rule of metaphorical thinking, which means showing the multiple meanings of a polysemy to students in a systematically related way. By this way, students may get a better understanding of the word and store it in the long-term memory. Owing to the existence of metaphor, we can use a small amount of words to describe the countless things and abstract concepts around us, to express our rich feelings. 


\subsection{Conceptual Metaphor and Idioms}

Any well-developed language contains a large number of idioms. They are the reflection of culture. For a long time, mechanical retention is widely used in idiom learning. However, the efficiency is not so good that students find difficult to understand idioms deeper meanings and easily forget what they've learned. Lakoff suggested that idioms are motivated by conceptual mappings: "what it means for an idiom to 'be natural' or 'to make sense' is that there are independently existing elements of the conceptual system that links the idiom to its meaning" (Lakoff, 1987: p. 449). It is effective to learn idioms through conceptual metaphors which can map knowledge of two different domains into correspondence.

Metaphor, as one of the cognitive mechanisms, constitutes the conceptual motivation for idioms. This is the reason why most of the idioms are explainable (Gibbs \& Nayak, 1989). Therefore, teachers can explain them with the aid of conceptual metaphors such as "Anger Is Fire". When we draw a fine distinction among "to spit fire", "smoke come out of ears" and "to be burned up", teachers ought to guide students to use their own experience and knowledge of "fire". All the three phrases mean "be angry". In "to spit fire", we infer from the conceptual domain of "fire" that if the fire becomes uncontrollable, it will be very dangerous for the person who lights the fire and the people around. So we can project the understanding onto "anger", when anger becomes very strong and difficult to control, it will be dangerous for the angry person and the people around; By the same token, if "smoke come out one's ears", the anger is under control; If someone "burns up", we can imagine that the person has completely lost control over reason, and this is, among the three phrases, the one which describes the most serious degree. It can be claimed that this metaphorical deduction is really helpful to our language teaching in that by means of it, we can effectively distinguish between the idioms which have similar meanings but differ in meaning to a certain extent.

\section{Conclusion}

Metaphor pervades our language and thought. As one of the most important theories of cognitive linguistics, conceptual metaphor theory brings a new cognitive way for people to cognize the world. It also provides us a new perspective in vocabulary teaching and learning in the EFL context. Teachers should first eliminate the traditional views of vocabulary, then teach the basic knowledge concerning the conceptual metaphor theory, i.e., teach students how to recognize, understand and use metaphor. At last, they also cannot ignore the cultivation of students' metaphorical competence, and encourage them to think, express, understand in target language metaphorically. It can be claimed that metaphorical teaching helps students to improve their creativity and imagination and arouse their learning enthusiasm and interests. To large extent, it helps learners to learn English vocabulary thoroughly, systematically and efficiently.

\section{References}

Gibbs Jr., R. W., Nayak, N. P., \& Cutting, C. (1989). How to Kick the Bucket and Not Decompose: Analyzability and Idiom Processing. Journal of Memory and Language, 28, 275-304. http://dx.doi.org/10.1016/0749-596X(89)90014-4

Johnson, M. (1987). The Body in the Mind: The Bodily Basis of Meaning, Imagination, and Reason. Chicago, IL: University of Chicago Press.

Lakoff, G. (1987). Women, Fire and Dangerous Thing. Chicago, IL: University of Chicago Press. http://dx.doi.org/10.7208/chicago/9780226471013.001.0001

Lakoff, G., \& Johnson, M. (1980). Metaphors We Live By. Chicago, IL: The University of Chicago Press.

Murcia, M., \& Rosensweig, F. (1979). Teaching Vocabulary in the ESL Classroom. Rowley, MA: Newburg House.

Ungerer, F., \& Schmid, H. J. (2008). An Introduction to Cognitive Linguistics. Beijing: Foreign Language Teaching and Research Press. 